\title{
PAISAGENS DO ATENDIMENTO EDUCACIONAL ESPECIALIZADO
}

\author{
CARLA BEATRIS VALENTINI
}

Doutora em Informática na Educação (UFRGS). Professora do Curso de Pedagogia da Universidade e do Programa de Pós-Graduação em Educação, Universidade de Caxias do Sul (UCS), RS. ORCID: https://orcid.org/0000-0003-0355-7712 E-mail: carlabeam@gmail.com

\section{RONIELE BELUSSO}

Mestre em Educação (UCS). Bacharel em FarmáciaUniversidade de Caxias do Sul (UCS), RS. ORCID: https://orcid.org/0000-0001-9836-8505. E-mail: ronielebelusso@yahoo.com.br

\section{SÔNIA REGINA DA LUZ MATOS}

Doutora em Educação (UFRGS). Professora do Centro de Filosofia e Educação e do Programa de Pós- Graduação em Educação da Universidade de Caxias do Sul (UCS), RS. ORCID: http://orcid.org/0000-0002-3946-5628. E-mail: srlmatos@ucs.br 


\section{RESUMO}

O presente estudo tem por objetivo evidenciar os saberes presentes nos registros escolares de alunos que frequentavam o Atendimento Educacional Especializado (AEE). Desenvolveu-se um quadro teórico com alguns entendimentos sobre os conceitos de poder e saber, bem como o funcionamento da inclusão escolar na legislação. Para orientar este estudo, tomou-se a cartografia como inspiração, definindo-se duas pistas/instrumentos. Esses se constituíram do caderno de anotações e dos registros escolares normativos. O caderno de anotações identificou um documento de produção escolar que foi de encontro com todos os documentos oficiais buscados. Essa produção ganhou o contorno de saber produzido pela escola, sendo denominada Saberes Curriculares de um Currículo Adaptado. Nos registros escolares normativos, encontraram-se termos/expressões que identificavam o indivíduo com necessidades educativas especiais. A partir desses registros, foi possível identificar vestígios de saberes psicológicos e médicos, os quais foram denominados noções de um saber psicológico e noções de um saber médico. A produção desta cartografia, a partir dos registros do caderno de anotações e dos registros normativos da escola, evidenciou três saberes que se fizeram constantemente presentes. Tais saberes conectam-se o tempo inteiro. Entretanto, um deles - o saber curricular de um currículo adaptado -, para poder funcionar, precisa de outros dois - as noções de um saber psicológico e as noções de um saber médico..

Palabras Claves: Atendimento Educacional Especializado, Cartografia, Inclusão.

\section{LANDSCAPES OF SPECIALIZED EDUCATIONAL ASSISTANCE}

The objective of this study has of evidencing the knowledge of school records from students who attended the Specialized Educational Assistance (SEA). It was developed a theoretical framework with some information about the concepts of power and knowledge, as well as school inclusion functioning in relation to legislation. To guide this research, cartography was used as inspiration, through the definition of two clues/instruments. They were the notebooks and the normative school records. The notebook identified a school production document which met all the searched official documents. This production received the knowledge form produced by school, called Curricular Knowledge of an Adapted Curriculum. In the normative school records, there were terms/expressions which identified the individual with special educational needs. From this information, it was possible to verify traces of psychological and medical knowledge, which were called notions of a psychological knowledge and notions of a medical knowledge. The production of this cartography, from notebook records and from school normative records, evidenced that three types of knowledge were constantly present. Such types of knowledge connect to each other all the time. However, the Curricular Knowledge of an Adapted Curriculum needs two other types of knowledge to properly function, the notions of a psychological knowledge and the notions of a medical knowledge.

Key-words: Specialized Educational Assistance, Cartography, Inclusion. 


\section{PAISAJES DEL ATENDIMIENTO EDUCACIONAL ESPECIALIZADO}

El presente estudio tiene por objetivo evidenciar los saberes presentes en los registros escolares de estudiantes que frecuentaban el Servicio Educativo Especializado (AEE). Se desarrolló un cuadro teórico con algunos entendimientos sobre los conceptos de poder y saber, así como el funcionamiento de la inclusión escolar en la legislación. Para orientar este estudio, se tomó la cartografía como inspiración, definiendo dos pistas/instrumentos. Estos se constituyeron del cuaderno de anotaciones y de los registros escolares normativos. El cuaderno de anotaciones identificó un documento de producción escolar que fue de encuentro con todos los documentos oficiales buscados. Esta producción ganó el contorno de saber producido por la escuela, siendo denominada Saberes Curriculares de un Currículo Adaptado. En los registros escolares normativos, se encontraron términos/ expresiones que identificaban al individuo con necesidades educativas especiales. A partir de estos registros, fue posible identificar vestigios de saberes psicológicos y médicos, los cuales fueron denominados nociones de un saber psicológico y nociones de un saber médico. La producción de esta cartografía, a partir de los registros del cuaderno de anotaciones y de los registros normativos de la escuela, evidenció tres saberes que se hicieron constantemente presentes. Tales conocimientos se conectan a todo el tiempo. Sin embargo, uno de ellos -el saber curricular de un currículo adaptado-, para poder funcionar, necesita de otros dos - las nociones de un saber psicológico y las nociones de un saber médico.

Palabras claves: Atención Educativa Especializada, Cartografía, Inclusión.

\section{PAISAGENS DO ATENDIMENTO EDUCACIONAL ESPECIALIZADO}

\section{Introdução}

Principalmente na última década, através das políticas educacionais, tem-se buscado estratégias, tanto na sala de aula quanto na sala de Atendimento Educacional Especializado (AEE), que permitam a participação equitativa de indivíduos que, até pouco tempo, vinham sendo excluídos da escola regular.

Frente a isso, o Atendimento Educacional Especializado (AEE), instituído pelo Decreto ${ }^{\circ}$ 6571/2008, caracteriza-se como a atual proposta do Ministério da Educação, que oferece suporte dentro das escolas regulares aos alunos com deficiência, transtornos globais do desenvolvimento e altas habilidades/superdotação nas classes comuns da rede regular de ensino (BRASIL, 2008).

O AEE abrange atividades, recursos e profissionais capazes de atuar na sala de recursos multifuncionais (local onde é realizado o AEE) e nas demais práticas desenvolvidas na escola. 
Este oferta "o conjunto de atividades, recursos de acessibilidade e pedagógicos organizados institucionalmente e continuamente" (BRASIL, 2011, s/p); prestado de forma complementar ou suplementar à formação dos alunos no ensino regular. (BRASIL, 2008).

Nesse sentido, a vontade de pesquisar foi direcionada a entender os saberes que se evidenciam nos registros escolares de alunos atendidos no AEE. A partir de tal questionamento, me aproximei da obra "Vigiar e punir" de Michel Foucault (2014), para pensar nos saberes presentes na instituição escolar, mesmo tendo conhecimento que, na atualidade, muitas pesquisas que tratam das práticas da instituição escolar estão voltadas tanto para o caráter disciplinar das sociedades modernas, quanto para biopolítica e governamento.

Partindo do entendimento que uma pesquisa traz apenas um pequeno recorte dentre as tantas teorizações, direcionamo-nos, apenas, para o caráter disciplinar, pois esse estudo busca olhar para os registros escolares, os quais compreendemos serem formados por saberes construídos a partir da técnica do exame e da vigilância, ou seja, práticas disciplinares.

\section{Pensar a Inclusão na Contemporâneidade}

A ideologia da inclusão defende uma escola plural e democrática. A escola, diante deste contexto, deve satisfazer as necessidades de todos os alunos, sejam quais forem as suas características, por meio de inovações das concepções e práticas pedagógicas à vista dos processos peculiares de ensino e aprendizagem. Nessa nova forma de ensino, a escola deve se adaptar às necessidades do aluno, com uma postura inversa à que tradicionalmente ocorria, em que o aluno precisava se adaptar à escola.

O AEE surge como um serviço ofertado em horário oposto a aquele que alunos frequentam a sala de aula regular, de forma que o aluno que o frequente poderá cursar regularmente o ensino regular. Esse atendimento foi criado visando a dar um suporte a alunos com necessidades educativas especiais, de modo a facilitar seu acesso ao currículo. Assim, o AEE deve ser ofertado, prioritariamente, na sala de recursos multifuncionais da própria escola ou em outra escola de ensino regular, podendo ser realizado, também, em centro de Atendimento Educacional Especializado da rede pública ou de instituições comunitárias, confessionais ou filantrópicas sem fins lucrativos, conveniadas com a Secretaria de Educação ou órgão equivalente dos Estados, Distrito Federal ou dos Municípios ofertados (BRASIL, 2009).

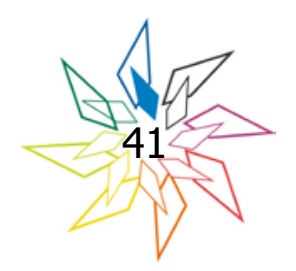


A proposta da inclusão tem em seu princípio ser contrária às formas tradicionais de ensino, de forma que as pessoas com necessidades educativas especiais aprenderiam de acordo com seu ritmo e suas possibilidades.

De acordo com Lockmann (2010) a inclusão escolar coloca em funcionamento uma rede que inclui movimentos pela participação do indivíduo em espaços sociais. Além disso, inclui um conjunto de legislações que se proliferam, organizando as práticas sociais e, principalmente, educacionais de modo que a inclusão escolar funcione conforme certas regras.

Colocar em prática a inclusão de pessoas com necessidades educativas especiais no sistema ensino implica em uma reorganização do sistema educacional, desconstruindo, assim, a cultura enraizada de exclusão, segregação e integração que perpassaram ao longo dos anos, a qual se associava à incapacidade dos sujeitos com deficiência de participar de ambientes comuns de ensino.

Ao nos aproximar dessas formulações, é possível perceber que em cada época as políticas públicas manifestam-se de maneiras diferentes, produzindo novas práticas, definindo tempos, espaços e campos de saberes, de forma a legitimar saberes e verdades fabricadas num sistema complexo de relações que envolvem poder.

No rastro dessas ideias, fazendo ponte com os conceitos empreendidos por Foucault (2014) sobre o poder disciplinar, a escola, como uma instituição disciplinar, tem em sua função o poder de fabricar indivíduos, por meio da criação de estratégias, posicionando o indivíduo em determinadas categorias para que assim consiga moldá-lo de acordo com as normas.

Isso porque a elaboração de um padrão de normalidade pelos saberes das ciências humanas e clínicas permitiu processos de classificação e fixação do indivíduo em categorias as quais oscilam entre a normalidade e anormalidade e, dessa maneira, tornaram possível a elaboração de políticas que possibilitaram a produção de individualidades adaptadas às exigências sociais.

Portanto, para que o indivíduo fosse capturado pela norma, foi preciso, antes, um saber sobre aquele que se captura. Com base em uma rede de saberes sobre o indivíduo com necessidades educativas especiais, esse deixou de ser estranho, e passou-se a ser enquadrado, posicionado e balizado o lugar que deveria ocupar para reestabelecer sua anormalidade. Para isso, surge o AEE funcionando como o tempo e o espaço que busca recuperar as curvas de normalidades mais desfavoráveis. 
Embora as práticas de inclusão escolar, na atualidade, parecem naturais, as mesmas estão imersas em relações de saber/poder que visam a posicionar o indivíduo em relação à norma.

Assim, entendo que as políticas inclusivas e mais precisamente o AEE apresentam-se num campo imerso por discursos e saberes que se cruzam, se encontram, se dissipam para pôr em funcionamento mecanismos de normalização aos indivíduos com deficiência, transtornos globais do desenvolvimento e altas habilidades/superdotação.

Frente aos saberes que se cruzam para pôr em funcionamento os mecanismos de normalização, penso que é possível fazer uma aproximação com o método cartográfico, o qual procura dar valor às conexões existentes entre os diversos acontecimentos, o que possibilita olhares diferentes sobre a realidade e seus atravessamentos.

\section{Deliminando alguns olhares}

A cartografia como metodologia não se caracteriza por um modelo ou passos a serem seguidos, cabe à cartógrafa criar sua trajetória, rotas de passagem na medida que passa a fazer parte do território de pesquisa. Assim, o trajeto criado pela cartógrafa será sempre novo, diferente, pois em cada pesquisa a mesma criará novas experiências, outros funcionamentos.

No processo de cartografar, expectativas devem ser deixadas de lado. É necessário que a pesquisadora esteja atenta e desacomodada, para que a mesma "possa, enfim, encontrar o que não conhecia, embora já estivesse ali” (KASTRUP, 2009, p. 49). Nesse sentido, é possível deslocar o olhar para perceber outras realidades, novas possibilidades.

Portanto, é importante ressaltar que a cartografia não constitui um modelo estrutural pronto, com traçados e regras estabelecidas. É uma metodologia que vai sendo construída na experimentação da pesquisadora (KASTRUP, 2009).

O fato de não contar com um processo metodológico de reprodução, mas que pertence à ordem da criação, me permitiu um espaço de liberdade para a criação da metodologia que possibilitasse a produção desta cartografia.

Assim, como aprendizes-cartógrafos, procuramos, nesta pesquisa, desenvolver uma atenção sensível aos vestígios de modo a estar aberta à captação do inesperado, à disposição para encontrar o que não procurava ou o que não sabia do que se tratava. Portanto, distanciando-nos de

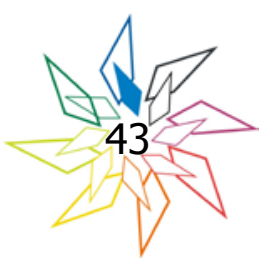


metodologias que procuram "representar o objeto ou processar informações acerca de um mundo supostamente já constituído.” (ALVAREZ; PASSOS, 2009, p. 131)

Deslocando-nos como quem parte em uma viagem, colocamo-nos a caminhar buscando diferentes paisagens, entregando-nos ao encontro que transforma maneiras de ver e abre para novos horizontes.

Inspiradas nas pistas que orientam a atitude do cartógrafo ao longo do processo de pesquisa, organizadas no livro Pistas do Método da Cartografia: Pesquisa-intervenção e produção de subjetividade, tais como: a cartografia como método de pesquisa-intervenção; o funcionamento da atenção no trabalho do cartógrafo; cartografar é acompanhar processos; movimentos-funções do dispositivo no método; o coletivo de forças como plano da experiência cartográfica; cartografar é habitar um território existencial; pôr uma política de narratividade; e diário de bordo de uma viagem-intervenção, buscamos construir as pistas/instrumentos ${ }^{1}$ para nortear-nos na produção desta pesquisa.

Assim, definimos algumas pistas/instrumentos ${ }^{2}$ que julgamos importantes, tendo em vista a problemática da pesquisa, para dar visibilidades à paisagem escolar. As pistas/instrumentos compuseram-se do caderno de anotações e dos registros escolares. O caderno de anotações serviu para registrar os acontecimentos que convocaram a minha atenção/tensão e as impressões que vivenciei na trajetória cartográfica.

Os registros escolares normativos foram documentos concedidos pelas professoras do AEE. Tais compuseram-se: das fichas de encaminhamento ao espaço especializado, do informe de atendimento, dos pareceres descritivos, dos laudos, e da anamnese.

\section{Território Pesquisado}

O território pesquisado foi uma escola de ensino fundamental de um município da Serra Gaúcha, cuja Secretaria de Educação indicou para a investigação, após contato solicitando liberação para a pesquisa. No momento da pesquisa, de março a setembro de 2016, a escola

\footnotetext{
${ }^{1} \mathrm{O}$ termo instrumentos foi acrescentado pela autora desta pesquisa.

${ }^{2}$ Entendo que, ao mesmo tempo que o caderno de anotações e os registros se mostram como pistas que norteiam-me a pesquisa, também se constituem como instrumentos.
} 
contava com trinta professores que atendiam quatrocentos e cinquenta e três alunos, da Educação Infantil ao nono ano do Ensino Fundamental.

A sala de recursos multifuncionais, onde é realizado o Atendimento Educacional Especializado, ocupa um espaço dentro do conjunto de salas de aula regulares, ou seja, de circulação de todos. Seu espaço interno é pequeno, com aproximadamente $14 \mathrm{~m} 2$.

Os atendimentos são realizados em dois turnos - manhã e tarde - por duas professoras, uma em cada turno. Nesse espaço, circulam, ao todo, noventa e dois alunos por semana, os quais recebem atendimento individual e em grupo. Destes, oitenta e três são considerados alunos com dificuldades de aprendizagem ${ }^{3}$, sem comprovação clínica, e nove alunos são considerados com necessidades educativas especiais, que apresentam diagnóstico clínico.

\section{Paisagem I: Caderno de Anotações}

Ao fazer uma leitura detalhada do caderno de anotações, foi possível produzir a noção de Currículo Adaptado - documento exigido pela escola ao professor que tenha em sua sala de aula aluno com necessidades educativas especiais. Vale destacar que esse documento parece ir de encontro com todos os documentos oficiais buscados, pois não há menção, nestes últimos, sobre o documento Currículo Adaptado ou sobre o tipo de estrutura que a escola propõe.

O Currículo Adaptado na escola pesquisada é um documento que deveria ser produzido pelos professores da sala de aula regular, para trabalhar com os alunos com necessidades educativas especiais. Para cada aluno com necessidades educativas especiais, o professor da sala de aula regular deveria produzir um documento específico a sua necessidade, visando a auxiliá-lo na condução do processo de ensino e aprendizagem do aluno.

Diante disso, a gestão da escola orientava os professores da sala de aula regular que a cada início de trimestre se produzisse um documento para cada aluno com necessidades educativas especiais. Depois de produzido, uma cópia do documento deveria ser entregue à coordenação escolar.

A partir da definição do documento denominado pela escola de Currículo Adaptado, buscamos olhar para a legislação que traz sobre as adaptações curriculares. Pude perceber que,

\footnotetext{
${ }^{3}$ As dificuldades de aprendizagem são condições que interferem na construção e desenvolvimento das funções cognitivas e que não apresentam um diagnóstico clínico.
} 
ambos, se diferenciam, visto que as adaptações curriculares trazem concepções sobre o que aluno deve aprender; em como e quando; as formas de organização do ensino para o processo de aprendizagem; e em como e quando avaliar. Já o Currículo Adaptado trata das habilidades, objetivos, estratégias e avaliação, de modo a ter características de um planejamento.

Frente à discordância entre o que a legislação propõe sobre adaptações curriculares com o que a escola produz - Currículo Adaptado -, direcionamos o olhar para a legislação, de forma a verificar se havia alguma menção sobre o documento escolar e forma de estruturação que a escola pesquisada propõe. Nesse direcionamento para a legislação, não encontramos algo que mencionasse o termo "Currículo Adaptado", mas com o Plano de Desenvolvimento Individual (PDI).

A partir do que propõe Poker et al. (2013) sobre o PDI, foi possível constatar que o documento Currículo Adaptado apresenta alguns traços do Plano de Desenvolvimento Individual, entretanto de uma forma simplificada. Dessa forma, a produção do Documento, o qual é produzido pelo professor da sala de aula, seria uma maneira que a escola encontrou para cumprir com o que a legislação preconiza em relação aos alunos que apresentam necessidades educativas especiais, visto que na mesma o professor do AEE não constrói o PDI em conjunto com os professores da sala de aula e nem o professor da sala de aula elabora as adaptações curriculares.

Dessa forma, nessa pesquisa, a noção de Currículo Adaptado ganha o contorno de saber produzido pela escola. Esse, é denominado, aqui como Curricular, pois é único, singular e da produção exclusiva dessa escola

Diante da singularidade do Currículo Adaptado pela instituição escolar pesquisada, pode estar ocorrendo certa resistência por parte desta em se adequar ao que vem sendo preconizado pelas normativas oficias quanto à elaboração do PDI e às Adaptações Curriculares.

Ao trazer tal premissa é possível articular com os conceitos de Foucault (2003, p. 232), o qual afirma que "as relações de poder suscitam necessariamente, apelam a cada instante, abrem a possibilidade a uma resistência"; pois, o poder quando exercido não apenas oprime, mas também produz comportamentos e efeitos sobre as pessoas ou a sociedade.

Dessa forma, entendemos que, não seguir o que está imposto pelo poder, ou seja, pela autoridade normativa, trata-se de desviar das normativas, de resistir ao comando das táticas de poder e assim desafiar a estabilidade que o poder procura manter. 
De acordo com Foucault (1979, p. 241) "jamais somos aprisionados pelo poder: podemos sempre modificar sua dominação em condições determinadas e segundo uma estratégia precisa". Portanto, nota-se que, por mais que as normativas orientam e norteiem as adaptações curriculares, isso não garante que tais documentos sejam compreendidos, aceitos e aplicados pelos professores da escola, pois, nas relações de poder, há sempre a possibilidade de condição de resistência.

A resistência afrouxa os "nós" do poder, rompe com a suposta estabilidade que ele objetiva manter, entretanto ela também reorganiza, pois a resistência tem o mesmo valor de amplitude e características que o poder. Ela é "tão inventiva, tão móvel, tão produtiva quanto ele" (FOUCAULT, 1979, p. 241); ou seja, ao mesmo tempo em que a resistência se opõe ao poder, não cumprindo com o preconizado pelas normativas legais, ela é capaz de produzir algo novo e singular que recebe a denominação de Currículo Adaptado.

Por sua vez, a produção do Currículo Adaptado também é capaz de estabelecer novas relações de poder, que poderão suscitar a invenção de novas formas de resistência, pois esta não se opõe ao poder, devido a ela fazer parte do seu próprio funcionamento.

Assim, na instituição escolar, existe uma resistência ao poder disciplinar das legislações que procura saídas, de maneira a agir de acordo com suas próprias normas, e ignorando as verdades absolutas produzidas pelas normativas oficiais que tendem a determinar a elaboração das adaptações curriculares e do PDI.

\section{Paisagem II: Registros Escolares Normativos}

Nessa paisagem procuramos voltar a atenção para pista/instrumento e registros escolares. Dessa forma, localizamos cinco tipos de registros nas pastas dos nove alunos que recebiam atendimento na sala de AEE. Estes estavam arquivados na sala de AEE e na sala dos professores. Os registros constituem-se por: 1) ficha de encaminhamento ao espaço especializado; 2) informe de atendimento; 3) pareceres descritivos; 4) anamnese; 5) laudo.

Ao olhar para os diferentes registros escolares de alunos com necessidades educativas especiais, verificamos certa regularidade nos termos e expressões que os narravam. Tais expressões classificavam e posicionavam o aluno em situações de aprendizagem.

Frente a essa constatação, voltamos para os conceitos de Foucault (2014), buscando produzir as visibilidades dessa produção. $\mathrm{O}$ autor traz em seus estudos algumas considerações sobre os rearranjos das questões de poder-saber sobre os corpos, que me parecem importantes. De acordo 
com Foucault (2014, p. 134), a partir do século XVIII, o corpo passou a ser visto como "objeto e alvo de poder". Assim, em alguns momentos se fez necessário sua submissão e utilização, em outros se fez importante o conhecimento e explicação do mesmo (FOUCAULT, 2014).

Os diferentes saberes científicos, característicos da modernidade, tiveram como ponto de apoio o corpo do homem. Portanto, o corpo passou a ser alvo de indagações das ciências emergentes, entre essas a Psicologia e a Medicina.

A Psicologia, como um saber em torno do par "função x norma" (FILHO; TRISOTTO, 2007, p. 08), desenvolve conceitos sobre corpo, alma e psique com a finalidade de explicar os fenômenos humanos.

Como um saber que gira em torno da norma, a psicologia passou a classificar e controlar os indivíduos frente aos aspectos da conduta humana, de maneira a enfatizar o patológico em detrimento do normal.

Por sua vez, no campo da Medicina, com a evolução da Medicina clássica para a Medicina moderna, o olhar clínico começa a penetrar no corpo, de forma a tornar visível o que se encontrava até então obscuro. A partir disso, a Medicina buscou preservar a vida da população, ou seja, "uma Medicina que vai ter, agora, a função maior de higiene pública, com organismos de coordenação dos tratamentos médicos, de centralização da informação, de normalização do saber, (...) de campanha de aprendizado da higiene e da medicalização da população" (FOUCAULT, 1999b, p. 291).

Assim, a Medicina buscou definir os modos de vida que julgava adequados, de forma a prescrever hábitos de higiene, alimentação, práticas de exercícios, entre outros. Frente a isso, os saberes médicos começaram a produzir regras para serem seguidas por todos, os quais objetivaram controlar e normatizar o indivíduo para que o mesmo tivesse uma condição de vida saudável (CRHISTOFARI, 2014).

Portanto, é possível perceber que os saberes científicos vieram para moldar o corpo no sentido da utilidade, da sua função produtiva. Esses saberes passaram a ser intensamente reconhecidos e implementados, de modo que atravessaram diversas instituições, entre elas, a instituição escolar.

Nesse sentido, Lockmann (2010) comenta que tanto os saberes da Psicologia como os saberes médicos se inseriram no campo da educação visando a construir teorias a respeito do desenvolvimento da criança. 
Nessa lógica, voltamos a olhar para os registros escolares, de forma a observar as recorrências e regularidades de saberes que se evidenciavam. Assim, pude perceber termos/ expressões sobre o sujeito com necessidades educativas especiais envolvendo: relacionamento, cognição, comportamento, emoção, alterações orgânicas, bem como sugestões que se remetiam ao aluno com necessidades educativas especiais.

Os registros traziam uma forma repetitiva para definir tais sujeitos, quase "universal" de descrição sobre os mesmos, de modo a parecer descrever sempre o mesmo aluno, com marcas de anormalidade. Frente a isso, de acordo com as similaridades dos termos/expressões, elegemos um conceito central que os definia, ou seja, os termos/expressões que envolviam cognição, comportamento, emoção e relacionamento defini como condutas. Já os termos/expressões que evolviam alterações orgânicas e sugestões/prescrições, definimos como diagnóstico.

Assim, definidos os conceitos centrais dos termos/expressões e partir dos entendimentos sobre a Psicologia e a Medicina, determinei o conceito condizente às condutas: noções de um saber psicológico e o conceito condizente a diagnóstico: noção de saberes médicos.

Ao olhar para os registros produzidos pela escola, foi possível perceber vestígios de um saber psicológico em alguns termos/expressões que "identificam" o sujeito com necessidades educativas especiais. Tais termos estavam presentes nas fichas de encaminhamento ao espaço especializado e nos informes de atendimentos. Assim, agrupamos os temos/expressões que identificavam os alunos com necessidades educativas especiais separando-os em relacionamento, emoção, cognição, comportamento, conforme demonstramos a seguir. Ressaltamos que os termos/expressões são cópias fiéis dos registros. Por essa razão, estão em itálico.

No quesito relacionamento com o professor e colegas, encontram-se expressões descrevendo um aluno que: não tem problema porque é muito quieto; é educado com o professor e colegas, porém bastante tímido; respeita as normas de boa convivência; é respeitoso com a professora; era meio intriguento, mas não observo mais essas atitudes; está constantemente em conflito; obedece comandos; respeita regras e as pessoas com quem convive; tem dificuldade em atender ordens e executá-las.

Quanto à questão emocional, os documentos trazem termos adjetivando o aluno, tais caracterizam-se por: inseguro; isolado; quieto; baixa autoestima; riso imotivado; timidez excessiva. 
Em relação a cognição também é possível encontrar adjetivações ao narrar o aluno. Essas se constituem por: dispersivo; desatento; olhar distante.

No quesito comportamento, há relatos de um aluno: retraído; sonhador; birrento; inquieto; apático; que precisa sair da sala para vomitar ou cuspir; que poucas vezes demonstrou interesse em realizar as atividades e em prestar atenção.

A presença de termos/expressões nos documentos, envolvendo relacionamentos, comportamentos, emocional e cognição demonstram que a Pedagogia busca apoio nos saberes do campo da Psicologia para identificar as marcas de anormalidade do sujeito. São termos/expressões que marcam o sujeito, as condições de aprendizagem, mas também que cria um estereótipo e define um sujeito com necessidades educativas especiais.

Dessa forma, no ambiente escolar, a norma age ininterruptamente. Ela enquadra, determina os gestos, aptidões e que de fato acaba pondo à margem o indivíduo que destoa do padrão estabelecido.

Há um processo de comparação que possibilita o professor identificar os alunos que se assemelham entre si e consequentemente uma identificação e classificação de alunos com necessidades educativas especiais.

A escola, como um espaço que está ligado a ideias da normalização, vigilância e exame, torna-se um local profícuo para, por exemplo, saberes do campo da Psicologia, pois possibilitam conhecer o aluno que apresenta necessidades especiais e ao mesmo tempo aproximá-lo de tecnologias que permitam sua correção. Portanto, trazer todos para normalidade se torna um imperativo da sociedade atual. Entretanto, para isso se torne possível, precisa-se conhecer quem está nas extremidades da norma.

Há um processo de comparação que possibilita o professor identificar os alunos que se assemelham entre si e consequentemente uma identificação e classificação de alunos com necessidades educativas especiais. Dessa forma, no ambiente escolar, a norma age ininterruptamente. Ela enquadra, determina os gestos, aptidões e que de fato acaba pondo à margem o indivíduo que destoa do padrão estabelecido.

Para isso, o Atendimento Educacional Especializado, com suas estratégias, desenvolverá saberes sobre eles e tentará corrigi-los e discipliná-los, uma vez que, no AEE, será disponibilizado ao aluno com necessidades educativas especiais os "recursos de acessibilidade e estratégias 
que eliminem as barreiras para sua plena participação na sociedade e desenvolvimento de sua aprendizagem" (BRASIL, 2009, p. 01). Nesse sentido, na escola inclusiva, criam-se técnicas que fazem com que esses indivíduos sejam adestrados e cheguem o mais próximo possível do considerado como um padrão de normalidade.

A partir de um conjunto de ações, o professor especializado controlará as atividades, o tempo, de modo a melhorar a vida dos sujeitos com necessidades educativas especiais, visto que dará a esses uma condição de vida o mais próxima possível da normalidade, tido como necessário pela sociedade disciplinar.

No exercício de suas atividades previstas, o professor do AEE, além de conhecer os recursos pedagógicos e de acessibilidade, necessitará de um conhecimento teórico acerca do desenvolvimento humano e das psicopatologias.

O professor do AEE, nesse cenário, será quem detém o poder e o saber sobre os indivíduos com necessidades educativas especiais, pois o mesmo é quem "realiza o atendimento educacional especializado, disponibiliza os serviços e recursos próprios desse atendimento e orienta os alunos e seus professores quanto a sua utilização nas turmas comuns do ensino regular" (BRASIL, 2008, s/p). Desse modo, cabe ao professor do AEE a tarefa da inclusão e, implicitamente, da normalização.

Nessa lógica de pensamento, podemos perceber como os saberes do campo da Psicologia têm influenciando, desde seus primórdios, as práticas pedagógicas, através da definição de condutas, padrões e aptidões dos indivíduos. Desse modo, penso que a norma continua se fazendo presente no ambiente escolar de forma que o indivíduo que destoe do padrão estabelecido seja ainda encaminhado para um processo de intervenção.

Dito isso, no que tange o contingente de alunos atendidos pela educação especial, percebemos que o diagnóstico médico ainda vem acompanhando os processos de escolarização dos indivíduos de modo a determinar o espaço escolar que os mesmos devem frequentar. Deparamos com uma intensa circulação de saberes do campo da Medicina na escola, seja por meio de encaminhamentos e avaliações por parte de professores e/ou por diagnósticos emitidos pelos próprios médicos.

Nos registros escolares percebemos os saberes da Medicina, atuando no espaço escolar, por meio de diagnóstico que determinam as alterações orgânicas dos sujeitos, bem como sugestões/ prescrições que objetivam a correção dos desvios, de maneira que torne o sujeito normalizado. 
Ao olhar para os laudos encontramos diferentes patologias presentes, como: déficit no processamento auditivo; desvios fonoaudiológicos; déficit na consciência fonológica; TDAH; dislexia; imaturidade neurológica; alterações na linguagem; epilepsia; anóxia perinatal; transtorno de habilidades escolares; transtorno de aprendizagem; encefalopatia crônica não progressiva da infância; paralisia cerebral; transtornos especificos do desenvolvimento das habilidades escolares; atraso cognitivo leve e perda auditiva.

Além das alterações orgânicas, nos laudos é possível encontrar sugestões/prescrições para os sujeitos, como: Sugere-se psicoterapia individual e familiar com o objetivo de reestruturar os papéis da dinâmica familiar; Necessária inclusão com atenção específica para portadores de dislexia; Avaliações de preferência orais; Necessita de atenção especial e reforço escolar; Necessita de atenção especial e reforço escolar; Necessária inclusão escolar e atendimento individualizado. Não deve ser exposto aos colegas (por ex. ler para os colegas) porque isso irá afetar ainda mais sua estima.

A partir disso, cabe ressaltar que a definição de deficiência, bem como a produção científica em relação à escolarização de alunos com necessidades especiais, historicamente, foi concedida pela área médica. Portanto, a deficiência esteve permeada pela compreensão de que características biológicas era a explicação para o insucesso escolar. Assim, as práticas pedagógicas foram fortemente influenciadas pelos saberes da Medicina, com o objetivo terapêutico de corrigir pessoas com deficiência.

O diagnóstico clínico definiu o lugar que os alunos deveriam frequentar, ou seja, sempre se ocupou da educação dos sujeitos da educação especial. A partir disso, não é surpresa a escola continuar a manter-se refém de laudos para a tomada de decisões pedagógicas.

Nesse sentido, compreendemos que, ainda hoje, normalidade e diagnóstico parecem definir os objetivos de ensino, pois de posse do diagnóstico alteram-se currículos, formas organizativas do trabalho pedagógico e métodos de ensino.

O saber médico segue tomando conta e definindo espaços, afirmando que as causas dos problemas estariam em doenças, o que, muitas vezes, torna-se um aliado no processo escolar e um grande desafio a ser superado diante do projeto de inclusão escolar. Confere-se ao médico a autorização de falar dos problemas educacionais, pois parece que o professor não se autoriza a falar do que ele conhece, dos saberes que legitimam sua profissão. Tais recomendações parecem descaracterizar a função precípua do professor de ensinar. 
De maneira a continuar dando visibilidade aos registros escolares, pudemos perceber uma prática discursiva pautada também no saber médico nas fichas de encaminhamento ao espaço especializado, nos informes de atendimento e anamneses. Tal prática caracteriza-se pelas seguintes alterações orgânicas: Dificuldades auditivas; TDAH associado à dislexia; distúrbio na fala; fimose; dificuldades motoras; disléxico; CID R48.0; TDAH; CID F90; distúrbio motor; bronquite asmática; suspeita de problemas na decodificação auditiva e disléxica; hipermetropia; amarelão; depressão; epilepsia, distúrbios na visão; distúrbios neurológicos; pneumonia; bronquite alérgica.

Ao olhar para as alterações orgânicas descritas nos registros escolares, penso que a escola ainda olha com lentes provenientes da clínica médica para os alunos com necessidades educativas especiais, de maneira a extrair o máximo de verdade sobre o indivíduo, anotando cada sintoma apresentado, pré-diagnosticando e classificando cada indivíduo.

Entendemos que, a partir de tais lentes, sustentam-se fazeres e dizeres por meio de um viés científico, o que gera certa "legitimidade" das causas da não aprendizagem, que passa a não ser mais um problema que diz respeito à questão pedagógica, mas torna-se algo inerente ao indivíduo. Nessa lógica, a deficiência passa a ser reduzida ao traço biológico decorrente da influência da Medicina na educação especial. O indivíduo parece entrar para o ambiente escolar com a marca de sua anormalidade.

O olhar atento e vigilante da instituição escolar visa a atuar capturando os detalhes dos indivíduos, analisando-os, diferenciando-os, ou seja, dando visibilidade as suas singularidades. Esse processo possibilita também que seja realizada uma intervenção no que compromete os problemas de aprendizagem do indivíduo.

Compreendemos, assim, uma apropriação do discurso pedagógico aos saberes da Medicina, de modo a produzir verdades sobre os sujeitos, sobre suas limitações, seu desenvolvimento, sua aprendizagem. Frente a isso, podemos perceber que, em tempos de inclusão, saberes advindos da modernidade como psicológicos e médicos ainda ocupam um lugar de legitimidade, historicamente construído no espaço escolar. Apesar da pretensão das Políticas Públicas em reestruturar o sistema de ensino, ainda se observam nos ideais da inclusão a perpetuação de uma visão clínica notadamente influenciada pelos saberes da Psicologia e Medicina, com uma atenção exacerbada ao distúrbio, de forma a observar-se a constante classificação dos alunos e a necessidade do saber especialista. 


\section{Final da viagem..., mas sem esgotar as paisagens}

Inspiradas na cartografia e com uma problemática que busca olhar para os saberes que se evidenciam nos registros escolares de alunos atendidos no AEE, tentamos produzir uma maneira de ver e compreender, em meio a tantas, o que, muitas vezes, se torna habitual e não problemática.

Atentamos para a questão disciplinar, descrita por Foucault (2014), utilizada nos séculos XVIII e XIX pela instituição escolar. Nessa incursão pela mesma, pudemos perceber que a escola contemporânea ainda faz uso de alguns recursos e mecanismos disciplinares descritos pelo referido autor. Dentre esses, destacamos o exame e a vigilância, os quais permitem à escola acumular registros, documentos e informações sobre cada aluno, transformando o mesmo em singularidades observáveis e mensuráveis.

O professor, com um conjunto de informações sobre o aluno, constituirá um saber, seja sobre seu processo de aprendizagem, seja sobre a maneira como ele se comporta. A partir disso, os indivíduos são identificados, classificados, diferenciando-os conforme sua normalidade/ anormalidade.

Uma vez que foge da norma, o indivíduo deverá ser corrigido. Dessa forma, pensamos que, em algumas situações, as políticas educacionais nacionais inclusivas tornam-se um conjunto de estratégias que ajudam a investir na norma, de maneira que atos, ações e comportamentos de indivíduos com necessidades educativas especiais possam operar de acordo com certos padrões de normalidade. Dentre as estratégias, é possível destacar as adaptações curriculares para dar conta daqueles que não se localizam dentro das normas da sociedade e passam a ocupar os espaços educacionais regulares.

Entretanto, nos registros escolares da Paisagem I desta pesquisa foi possível evidenciar a produção de um documento denominado Currículo Adaptado, que difere do proposto pela legislação que trata das políticas educacionais nacionais, na área da Educação Inclusiva.

Ao olhar para a produção do Currículo Adaptado, podemos encontrar um documento de criação singular da escola e que rompe com o que prevê a legislação vigente sobre as adaptações curriculares. A produção desta pesquisa dá visibilidade a um Currículo Adaptado não prescrito nas leis. A escola parece subverter o que está posto na legislação sobre adaptações curriculares, pois ela produz um documento denominado Currículo Adaptado que tem a estrutura de um planejamento, tendo por base dois saberes, o médico e o psicológico. 
Entendo este documento como um saber único que aciona e produz saberes médicos e psicológicos, de forma a não haver mais fronteiras entre eles. Com isso, quero dizer que a instituição escolar introduz e apropria-se do diagnóstico médico de forma que esse determina se o indivíduo necessitará ou não da produção do Currículo Adaptado.

Caso o indivíduo necessite da produção do Currículo, o professor fará uso dos saberes do campo da Psicologia sobre o desenvolvimento humano e a psicopatologia para enquadrar o aluno na etapa e nos problemas de desenvolvimento. A partir dessa postura clínico-avaliadora, o professor poderá delimitar os objetivos, as habilidades e estratégias do Currículo Adaptado que serão trabalhadas com o aluno com necessidades educativas especiais.

Com a prática do Currículo Adaptado, entendemos que, ao mesmo tempo em que há produção de singularidade, também há uma prática conservadora clínica-terapêutica baseada nos saberes advindos da modernidade, entre eles os saberes da Psicologia e da Medicina, que seguem uma linha dura.

Assim, nesta pesquisa, a partir dos registros do caderno de anotações e dos registros normativos da escola, foi possível evidenciar três saberes que se fizeram intensamente presentes, como: saberes curriculares de um Currículo Adaptado; saber médico e o saber psicológico. Tais saberes conectam-se o tempo inteiro, mas um deles, o saber de um Currículo Adaptado, para poder funcionar precisa de outros dois, o saber médico e o saber psicológico.

O Currículo Adaptado torna-se um artefato da maquinaria escolar, engendrada em relações de poder-saber escolar, que põem em funcionamento estratégias de normalização e fabricação de um determinado indivíduo, tornando-o, assim, um produto dos procedimentos disciplinares.

Dessa forma, a instituição escolar, mesmo diante das reformas propostas pelas políticas inclusivas, continua funcionando como uma máquina que visa à produção de um determinado indivíduo baseada em saberes científicos, pois é a partir desses, associados a certos aparatos e mecanismos disciplinares, que se torna possível um conhecimento minucioso do Saber de um Currículo Adaptado Saber psicológico Saber médico 96 indivíduo. Esse conhecimento é que permitirá a criação de determinadas práticas e estratégias que possibilitam sua normalização.

Assim, por meio desta pesquisa, foi possível que olhar para os saberes presentes nos registros para além da linearidade dos modelos convencionais, que apresentam uma metodologia pré-estabelecida, pois a cartografia nos permitiu fazer a montagem dos saberes e mostrar suas conexões e cruzamentos. 


\section{REFERÊNCIAS}

ALVAREZ, Johnny; PASSOS, Eduardo. Cartografar é habitar um território existencial. In: PASSOS, Eduardo; KASTRUP, Virgínia; ESCÓSSIA, Liliana da. (Orgs.). Pistas do método da cartografia: pesquisa-intervenção e produção de subjetividade. P. Alegre: Sulina, 2009.

BRASIL. Ministério da Educação. Política Nacional de Educação Especial na perspectiva da Educação Inclusiva. Brasília, MEC/SEESP, 2008.

BRASIL. Conselho Nacional de Educação. Câmara de Educação Básica. Resolução CNE/ CEB n ${ }^{\circ}$ 4, de 2 de outubro de 2009. Institui Diretrizes Operacionais para o Atendimento Educacional Especializado na Educação Básica, modalidade Educação Especial. Brasília, 5 out. 2009

BRASIL. Decreto $\mathbf{n}^{\circ} \mathbf{7 . 6 1 1}$, de 17 de novembro de 2011. Dispõe sobre a educação especial, o atendimento educacional especializado e dá outras providências. Brasília, 17 nov. 2011.

CHRISTOFARI, Ana Carolina. Modos de ser e de aprender na escola: medicalização (in) visível?. 2014. 174. Tese (Doutorado em Educação) - Programa de Pós-Graduação em Educação, Universidade Federal do Rio Grande do Sul, Porto Alegre, 2014.

FILHO, Kleber Prado; TRISOTTO Sabrina. A Psicologia como disciplina da norma nos escritos de M. Foucault. Revista aulas. Dossiê Foucault, n. 3, p. 1-14, dez 2006/mar. 2007.

FOUCAULT, Michel. Microfísica do Poder. 15 Ed. Rio de Janeiro: Graal, 1979.

FOUCAULT, Michel. Em defesa da Sociedade. Curso dado no Collége de France (19751976). Trad. Maria Ermantina Galvão. São Paulo: Martins Fontes, 1999.

FOUCAULT, Michel. Poder e saber. In: Motta, Manuel Barros da (Org.) Estratégia, poder saber. Coleção Ditos \& Escritos. Volume IV. R de Janeiro: Forense Universitária, 2003.

FOUCAULT, Michel. Vigiar e Punir. 42 ed. Petrópolis: Vozes, 2014.

LOCKMANN, Kamila. Inclusão escolar: saberes que operam para governar a população. 2010. 180f. Dissertação. Programa de Pós-Graduação em Educação, Faculdade de Educação da Universidade Federal do Rio Grande do Sul, Porto Alegre, RS, 2010 
KASTRUP, Virgínia. O funcionamento da atenção no trabalho do cartógrafo. In: PASSOS, Eduardo; KASTRUP, Virgínia; ESCOSSIA, Liliana da (Orgs.). Pistas do método da cartografia: pesquisa-intervenção e produção de subjetividade. Porto Alegre: Sulina, 2009.

POKER, Rosimar Bortolini et al. Plano de desenvolvimento individual para o atendimento educacional especializado. S Paulo: Cultura Acadêmica; Marília: Oficina Universitária, 2013. 